Research Article

\title{
Droplet Impact Phenomena in Fluidized Bed Coating Process with a Wurster Insert
}

\author{
T. Havaić, A.-M. Đumbir, M. Gretić, G. Matijašić (D), and K. Žižek \\ Faculty of Chemical Engineering and Technology, University of Zagreb, Zagreb, Croatia \\ Correspondence should be addressed to G. Matijašić; gmatijas@fkit.hr
}

Received 21 February 2018; Revised 30 May 2018; Accepted 16 July 2018; Published 7 August 2018

Academic Editor: Michael Harris

Copyright (c) 2018 T. Havaić et al. This is an open access article distributed under the Creative Commons Attribution License, which permits unrestricted use, distribution, and reproduction in any medium, provided the original work is properly cited.

\begin{abstract}
The aim of this study is to determine favorable process conditions for the coating of placebo tablets. Tablets made of microcrystalline cellulose are coated with hydroxypropyl cellulose polymer and Advantia ${ }^{\mathrm{TM}}$ Prime polymeric mixture film in lab-scale fluid-bed environment with a Wurster tube. In order to determine favorable process conditions (concentration, Wurster tube position, inlet air temperature, and atomization pressure), evaluation factors expressing process efficiency were calculated. Stereomicroscopy analysis provided good results with respect to the coating layer adherence and consistency. Results showed that the increased number of the coating cycles contributes to the desired featureless film morphology, when sufficiently high temperature and pressure are applied, thus resulting in high intra- and intertablet uniformity. Additionally, this paper analyzes the coating process from a mechanistic perspective of the underlying phenomena occurring on a tablet surface. Provided diagrams can help efficiently in detecting proper conditions that will result in coated tablets with strictly defined aimed properties. Process and formulation properties synergically result in a preferential occurrence of a deposition mechanism for all experiments conducted. Moreover, collision is found as a prevalent impact regime for the coating process studied. Finally, our intention here is to correlate hydrodynamic conditions and droplet breakup occurrence with a droplet diameter.
\end{abstract}

\section{Introduction}

Coating process is widely used in many diverse industries. Numerous process variables affect fluidized bed coating performance, thus influencing the product properties [1]. Complexity of the process can be overwhelmed by studying the process in detail using a multiscale approach [2]. High coating quality and higher process efficiency can be accomplished if the right process settings are strictly applied [3].

Coating of pharmaceuticals serves to enhance therapeutic, technological, and marketing properties of particular drugs. Among other common dosage forms, tablets emerge as the most popular solid oral dosage form. Coated tablets can provide optimal drug release profiles, helping enhance therapeutic performance, moisture protection, and protection from the gastric environment. Coatings are also convenient for incorporating another drug to avoid chemical incompatibilities or formula adjuvant.

Pharmaceutical industry emphasizes significance of coatings, being an important factor in releasing an active ingredient. Consequently, there is a growing interest in carrying out more efficient coating processes [4]. A great deal of practical problems arises with the proper selection of formulation and process properties. A good selection of process conditions is essential to avoid coalescence and breakage of the particle, as well as undesirable film formation mechanism, resulting in poor coating qualities.

Assorted purposes of coating specify the experimental program. The objective is to avoid tablet sticking on the equipment wall and prevent agglomeration, thus providing homogeneous coating thickness distribution on the tablet surface. It should be stressed that certain combinations of process properties lead to unevenly distributed coating thickness and irregular morphology. This results in a wide tablet-to-tablet coating variation and consequently may result in undesired variation in drug-release profiles [5], causing the process to be quite inefficient, therefore highly uneconomical [6].

The major advantage of the fluidized-bed process over drum coating is high level of film uniformity, since the film 
quality changes in line with the process conditions adjustment. Coating needs to be uniformly distributed on the tablet surface, while maintaining good mechanical properties. Certain alterations in process conditions (temperature, atomization air flow, solution concentration, etc.) strikingly affect the average size of the coating solution droplet. Droplet properties (size and velocity) directly affect the impact regime, hence on the film morphology and its final consistence.

The film coating process produces thin polymer-based coating with layer thickness varying from 5 to $50 \mu \mathrm{m}$, depending on the coating solution properties and the number of coating cycles applied. In the case of film coating, tablet weight increases only $2-5 \%$, that is much less to those applied to sugar coating where weight increase is up to $50 \%$. Weight reduction directly affects the tablet size and transport-related costs [7].

The main ingredient of coating solution used in the film coating process is a polymer. In most cases, it comes to cellulose esters, acrylic polymers, and copolymers. Being the key element, the polymer properties substantially influence the features of the coating layer. It is essential for excellent mechanical properties to coincide with good solubility, viscosity, and permeability. In order to meet the end-use requirement, more than one polymer component are combined [8].

Together with aforementioned specifications, coating needs to be compact, glassy, opaque, and affixed firmly. Extra ingredients are frequently added to ensure aimed coating performance.

Currently, industrial coating process optimization relies mostly on empirically determined conclusions. Furthermore, common coating quality factors are found to be complex to relate to process conditions alteration. For this reason, calculation-based adjustment of process settings in many cases gives poor result [6]. Another way is to conduct experimental research trying to reach desired product appearance.

Fluidized bed coating process variables being solid particles velocity, coating period, coating solution concentration and flow rate, viscosity, and droplet size directly affect applied film properties. Accurate and thorough interpretation of results can give a hint to the needed changes in process modeling. This way the optimization process can be accelerated and hence more affordable.

For successful process evolution, it is essential to detect the effect of all process and formulation properties on the underlying mechanisms controlling the process and therewith on the final process outcome. Regarding this, there is a strong need to carefully consider the coating process as a complex synergy of many events occurring in the coating process volume. These events correspond to three underlying phenomena. They are fluidization, spraying, and drying. We have to apply an adequate proper fluidization flow pattern for tablets, to reach spray droplets uniformly and to dry spray droplets at the suitable kinetics. These phenomena act simultaneously and thus competitively create the final coating performance.

With process and material properties, we are highly able to adjust the events on each tablet's surface in a manner we strive.
Accordingly, the main goal of this research is to comprehensively investigate the effect of many process variables on coating layer formation. In addition, we seek to understand droplet formation, to reveal its size and to provide an explanation of its spreading on a tablet surface. Factors that greatly influence the droplet characteristics are properties of atomizer (nozzle type and spray width), coating solution properties (viscosity, density, and surface tension), flow rates (air pressure), and temperature inside the coating unit [9]. Air stream plays a role in fluidization of particles, as well as evaporation of the excess solvent. Sudden evaporation leads to increase in viscosity. The progression of the droplet spreading over the tablet surface becomes limited, and coalescence may take over.

Additionally, there is a possibility that droplet will overdry before it hits the particle if the air is too hot. This problem is emphasized in the case of organic solvent appliance or when polymeric solution rapidly changes as the dry matter content increases.

1.1. Droplet Impact Regime. Among the most influential factors in coating layer formation, one can find droplet size. Many papers addressed the problem of understanding the effect of droplet formation and impact conditions on wetting dynamics [9-12]. However, a little attention has been paid to the exploration of other present phenomena such as drying, droplet-particle and droplet-droplet collisions, and so on.

Droplet deposition is considered to be a successful impact outcome. Adherence efficiency depends on momentum, angle of incidence, solution properties, and characteristics of the surface. Particles and droplets ratio indicates the dominant impact regime [9].

Calculation of impact efficacy can be based on relation of space surrounding the critical trajectory and projected tablet surface area, yet Cheng and Turton [13] pointed out unpredictable "shading" effect. Further papers appraise this remark, still leaving out other important details (turbulence, droplet shape, surface features, etc.) without proven contribution to the impact outcome, which must exist.

Dimensionless numbers, namely, Reynolds (Re), Ohnesorge ( $\mathrm{Oh}$ ), and Weber (We), have proven to be useful in explanation of the droplet formation process. They are highly able to nondimensionalise droplet breakup phenomenon and impact mechanism occurrence. Relationships of dimensionless numbers strongly define the droplet-surface impact model as well as coating mechanisms:

$$
\begin{aligned}
\operatorname{Re} & =\frac{v_{\mathrm{d}} \cdot d \cdot \rho}{\mu}, \\
\mathrm{Oh} & =\frac{\sqrt{\mathrm{We}}}{\operatorname{Re}}=\frac{\mu}{\sqrt{\rho \cdot d \cdot \gamma_{\text {liq }}}}, \\
\mathrm{We} & =\frac{\rho \cdot d \cdot v_{\mathrm{d}}^{2}}{\gamma_{\text {liq }}} .
\end{aligned}
$$

The lack of Weber number is that it does not take into account viscosity. There are some upgrades of the Weber 
dimensionless number. These are Ohnesorge $(\mathrm{Oh})$ and Laplace (La) numbers which include liquid viscosity. Toviakka [9] has found that high impact velocity of lowviscous tiny droplets stimulates the spreading. Accordingly, Pasandideh-Ferd et al. [14] have developed maximum spreading factor $\left(\xi_{\max }\right)$ expression:

$$
\xi_{\max }=\sqrt{\frac{\mathrm{We}+12}{3\left(1-\cos \theta_{a}\right)+4(\mathrm{We} / \sqrt{\mathrm{Re}})}} .
$$

The denominator comprises elements of restriction to spreading (solidification by drying, surface tension, and viscous losses). In view of the fact that droplet retraction is not included in this calculation, it only partially explains the issue of thin film formation.

Maximum spreading factor is the ratio of maximum droplet diameter after the impact on the solid surface when the droplet starts spreading and the mean diameter of the droplet before the impact.

Simple model by Asai et al. [12] excludes the contact angle. Meanwhile, it seems to work well in experiments with micron sized droplets:

$$
\xi_{\max }=1+0.48 \cdot \mathrm{We}^{0.5} \exp \left(-1.48 \cdot \mathrm{We}^{0.22} \mathrm{Oh}^{0.21}\right) .
$$

Another model, established by Roisman [15], likewise contains no variables. They noted that impact phenomena calculation based on energy balance is inaccurate and suggested mass and momentum balance of spread droplet and pin line. From the equation of the spreading factor through the conservation law of mass, the maximum spreading factor can be expressed:

$$
\xi_{\max }=0.87 \cdot \mathrm{Re}^{1 / 5}-0.40 \cdot \mathrm{Re}^{2 / 5} \mathrm{We}^{-1 / 2} .
$$

The impact regime map was adapted from Khoufech et al. [16]. The critical Ohnesorge number is considered as a boundary between the deposition and splashing impact model.

1.2. Droplet Size. The droplet size is estimated by the following empirical expression:

$$
\begin{aligned}
D_{50}= & 604.53 \cdot \frac{\gamma_{\mathrm{liq}}^{0.41} \cdot \mu^{0.32}}{\left(v_{\mathrm{REL}}^{2} \cdot \rho_{\mathrm{air}}\right)^{0.57} \cdot A_{\mathrm{G}}^{0.36} \cdot \rho_{\mathrm{sol}}^{0.16}} \\
& +330.71 \cdot\left[\left(\frac{\mu}{\gamma_{\mathrm{liq}} \cdot \rho_{\mathrm{sol}}}\right)^{0.17} \cdot\left(\frac{1}{v_{\mathrm{REL}}^{0.54}}\right)\left(\frac{\dot{M}_{\mathrm{sol}}}{\dot{M}_{\mathrm{air}}}\right)^{0.5}\right] .
\end{aligned}
$$

Nevertheless, estimation of the droplet size according to Waltzel's model for Sauter mean diameter gives more accurate results. Unlike other available empirical equations, this correlation takes the spray air pressure into account (8). Hede et al. [17] have done an exhaustive research study on the results of different correlations. They concluded that Waltzel's model gives substantial results on solution spraying, while other models are far more adjusted for suspension spray characterization:

$$
D_{32}=d_{0} \cdot 0.35 \cdot\left[\frac{\Delta p_{\mathrm{air}} \cdot d_{0}}{\gamma_{\mathrm{liq}}\left(1+\left(\dot{M}_{\mathrm{sol}} / \dot{M}_{\mathrm{air}}\right)\right)^{2}}\right]^{-0.4} \cdot(1+2.5 \cdot \mathrm{Oh}) .
$$

\subsection{Efficacy Assessment of Coating Process: Estimation of Parameters}

1.3.1. Intratablet Uniformity. Intratablet coating uniformity is a term used to describe the variation of coating thickness on a single tablet's surface. It is given as minimal coating thickness and the span of coating thickness distribution. Obtained film morphology is determined by the micrographic analysis. Coated tablets are usually sorted into predefined quality category, depending on the coating uniformity. Categories are afterwards ranked by the numeric quality score order. More recently, Raman spectroscopy $[18,19]$, near-infrared spectroscopy [20], terahertz pulsed imaging [21], and optical coherence tomography [22] have been used to determine the intensity of the colored coatings.

1.3.2. Intertablet Uniformity. Evaluation of the coating uniformity among the tablets in every single experiment is the most challenging part of coating quality assessment. Coefficient of variation $(\mathrm{CV})$ is defined as the ratio of the standard deviation to the mean:

$$
\mathrm{CV}=\frac{\sigma}{\bar{m}_{\mathrm{c}}}
$$

$$
\sigma=\sqrt{\frac{1}{N-1} \sum_{i=1}^{N}\left(m_{\mathrm{c}, i}-\bar{m}_{\mathrm{c}}\right)^{2}}
$$

\section{Experimental}

2.1. Tablets. Tablet cores used in experiments are roundshaped and are made of microcrystalline cellulose (MCC; Avicel ${ }^{\circledR}$ PH Microcrystalline Cellulose, FMC BioPolymer). Characterization was carried out on twenty randomly selected tablets. Averaged tablet's properties are presented in Table 1. The Erweka TBH 30 device was used to determine tablets' dimensions and hardness. Tablets were inserted in a star-shaped feeder and then automatically transported to the test station. At the test station, each tablet is first vertically pressed by the piston to measure thickness. Next, the diametrical compression test is performed on the same tablet. The tablet is pressed diametrically by the horizontal piston to measure the diameter. The force is then increased until the tablet breaks which is recorded as the amount of force (in Newtons) needed to break the tablet, and it corresponds to the hardness value.

From the features measured (Table 1), equivalent diameters (surface area and volume) were calculated and presented in Table 2. Waddell's sphericity factor was calculated as well according to the following equation: 
TABLE 1: Measured characteristics of the tablets-average values for 20 tablets.

\begin{tabular}{lc}
\hline Weight $(\mathrm{mg})$ & $75.2 \pm 5.2$ \\
Thickness $(\mathrm{mm})$ & $3.09 \pm 0.02$ \\
Diameter $(\mathrm{mm})$ & $5.01 \pm 0.02$ \\
Hardness $(\mathrm{N})$ & $62.00 \pm 6.22$ \\
\hline
\end{tabular}

TABLE 2: Calculated characteristics of tablet cores.

Equivalent volume diameter, $d_{\mathrm{V}}(\mathrm{mm})$

Equivalent surface diameter, $d_{\mathrm{S}}(\mathrm{mm})$

$4.88 \pm 0.01$

Waddell's sphericity factor, $\psi_{\text {Wa }}$

$5.29 \pm 0.01$

Tablet density, $\rho_{\mathrm{p}}\left(\mathrm{kg} \cdot \mathrm{m}^{-3}\right)$

$0.85 \pm 0.00$

$1276.3 \pm 85.6$

$$
\psi_{\mathrm{Wa}}=\left(\frac{d_{\mathrm{V}}}{d_{\mathrm{S}}}\right)^{2}
$$

Assessment of uncoated tablets friability was carried out using double drum tablet friability tester (J. Engelsmann, AG, Germany). The drums have an inside diameter of $287 \mathrm{~mm}$ and are $38 \mathrm{~mm}$ in depth. The friability test was performed according to European Pharmacopoeia [23]. Tablets are weighed before the test and after being exposed to mechanical abrasion. The percent of the mass loss of the tablet cores was calculated according to the following equation:

$$
F=\frac{m_{1}-m_{2}}{m_{1}} \cdot 100
$$

Obtained friability was $0.16 \%$. Results showed acceptable friability (must not exceed 1\%) for the tablets used according to European Pharmacopoeia [23].

Surface morphology of coated tablets was examined using the stereomicroscope SZX 16 (Olympus, Japan) at magnifications of 20x, 25x, 60x, and 64x. Tablet thickness, hardness, and diameter were determined with the Erweka TBH 30 tester (Erweka GmbH, Heusenstamm, Germany). Testing was conducted on 20 randomly selected tablets. Hardness, diameter, and thickness (Table 1) are expressed as the mean value of all measurements including error bars expressed as standard deviation of the measured values.

2.2. Coating Solutions. The coating film is obtained from aqueous solution of polymer powder mixture. Advantia Prime is a commercially available powder mixture. It contains hydroxypropyl methylcellulose (HPMC), hydroxypropyl cellulose (HPC), ethyl cellulose (EC), titanium dioxide, talc, iron oxide, silicon dioxide, polysorbate 80 , and polyethylene glycol (PEG). The aforementioned combination of ingredients promotes water solubility and ensures regulated release of the active pharmaceutical ingredient (API).

Advantia Prime properties are shown in Table 3.

Determination of rheological behavior and viscosity of the coating solution was conducted using a rotational viscometer DV III+ (Brookfield Engineering Laboratories, Inc., USA). Measurements were performed with SC4-21/SC4-13R spindle/chamber combination, and data were analyzed using
Table 3: Rheological properties of the Advantia Prime coating solution.

\begin{tabular}{lccc}
\hline Mass fraction of Advantia Prime & 0.02 & 0.05 & 0.10 \\
\hline Density $\left(\mathrm{kg} \cdot \mathrm{m}^{-3}\right)$ & 1008 & 1023 & 1036 \\
Viscosity $(\mathrm{mPa} \cdot \mathrm{s})$ & 1.71 & 15.60 & 87.80 \\
Surface tension $\left(\mathrm{mN} \cdot \mathrm{m}^{-1}\right)$ & 46.1 & 44.6 & 41.8 \\
\hline
\end{tabular}

Rheocalc software package (Rheocalc). Rheological diagrams showed a Newtonian behavior for all tested coating solutions with a constant viscosity during shearing.

The surface tension of coating solutions was measured according to the pendant drop method using a goniometer DataPhysics Contact Angle System OCA 20. All measurements were conducted at $23^{\circ} \mathrm{C}$. The surface tension was calculated from the geometry of the drop and density of the liquid (Table 3). While the droplet is suspended in the air, gravity and the surface tension act on it. The curvature of the drop at the equilibrium state is exactly mathematically defined by the Young-Laplace equation:

$$
\Delta p=\frac{2 \cdot \gamma_{\text {liq }}}{R} .
$$

2.3. Process Equipment. The coating process was performed in a laboratory fluidized-bed unit UniGlatt (Glatt $\mathrm{GmbH}$, Binzen, Germany) equipped with a Wurster insert (Figure 1).

The cone-shaped process chamber owns a small glass window for observing the fluidization occurrence. Twofluid nozzle is positioned under the bottom end of the Wurster tube (bottom spray mode) fixed in the center of the chamber. Coating solution and air stream contact takes place outside the nozzle. The position of the nozzle is fixed. The opening of the nozzle determines the spray angles and the droplet size. The opening is defined by the position of a small ring on the top of the nozzle. The upper side of the chamber contains a filter that prevents particles leaving the chamber. There is a plate on the bottom that enables compressor air distribution and saves the tablet cores from collapse.

2.3.1. Atomization Process: Two-Fluid Nozzle. Simplified models of two-fluid nozzle with the external mixing zone imply both fluids flow axially. Liquid runs through the central pipe of the atomizer, while air stream fills the outer pipe around it. Contact between the phases takes place in a mixing zone $\left(L_{\text {mix }}\right)$ outside the nozzle orifice (Figure 2). Air stream accelerates the liquid jet that exits the nozzle. Therefore, the same principle is used to establish desired relative velocity of any given solution droplets, hence defining the size of droplets in a spray [17].

When the liquid flow rate is considerably lower than air flow rate, droplets adopt the air velocity. In the case of increased liquid flow rate, droplets acquire certain velocity to the end of the mixing zone as follows:

$$
v_{\mathrm{d}}=\frac{v_{\text {air }}}{\left(1+\left(\dot{M}_{\text {sol }} / \dot{M}_{\text {air }}\right)\right)} \text {. }
$$




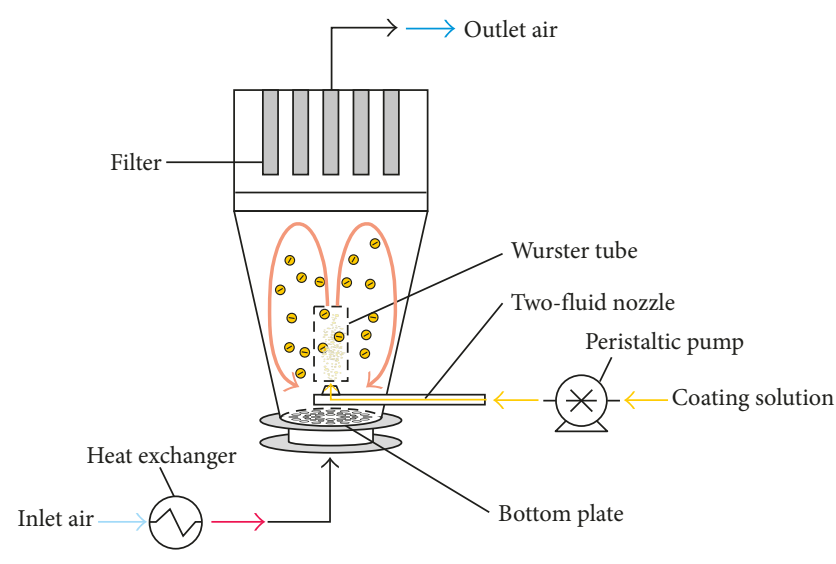

FIGURE 1: Schematic of the fluidized bed with a Wurster insert.

Air velocity was calculated according to the following equation:

$$
v_{\mathrm{air}}=\frac{\dot{V}_{\mathrm{air}}}{A_{\mathrm{G}}}=\frac{\dot{V}_{\mathrm{air}}}{(\pi / 4) \cdot\left(d_{\mathrm{G}}^{2}-d_{0 \mathrm{~V}}^{2}\right)} .
$$

The additional benefit of the atomization process is the rapid increase of the droplet surface, thus providing fast evaporation. Theoretically, maximum atomization efficiency can be reached. The tiniest droplets will be generated when $\left(\dot{M}_{\text {sol }} / \dot{M}_{\text {air }}\right) \rightarrow 0[13]$.

2.3.2. Coating Process Implementation. Two steps of the process were applied in order to perform coating successfully. Firstly, heating is activated in the process unit containing weighed portion of tablets. When the outlet air temperature appears constant, stationary conditions in the coating chamber are accomplished. The first dose of the coating solution is now being sprayed onto tablets. Transported through the peristaltic pump, solution is brought to the two-fluid nozzle. Coating solution is dosed in several cycles, each one lasting for 30 seconds and being followed by the drying period in the hot air stream for another 30 seconds.

Minimum fluidization velocity is calculated using empirical equation (16), which is valid for particles larger than $100 \mu \mathrm{m}[4,24]$ :

$$
\begin{aligned}
& v_{\mathrm{mf}}=\frac{\mu}{\rho_{\mathrm{air}} \cdot d_{\mathrm{p}}}\left[(11135.7+0.0408 \cdot \mathrm{Ar})^{1 / 2}-33.7\right], \\
& \mathrm{Ar}=\frac{\rho_{\mathrm{air}} \cdot d_{\mathrm{p}}^{3} \cdot\left(\rho_{\mathrm{p}}-\rho_{\mathrm{air}}\right) \cdot g}{\mu^{2}} .
\end{aligned}
$$

However, estimated values of the minimal fluidization velocities have been insufficient for tablet fluidization in the described experimental setting. Real values are therefore determined visually. The process conditions are shown in Table 4.

Table 5 summarizes combinations of temperature and atomization pressure as well as designation of experiments.

\section{Results and Discussion}

3.1. Coefficient of Variation (CV) and Content of Poorly Coated Tablets (PCT). A previous work presented by Matijašić et al. [25] was used as preliminary research to establish optimal process conditions. Table 6 summarizes the values of intertablet uniformity in terms of coefficient of variation (CV) and the content of poorly coated tablets (PCT) from previous research at different process conditions. All experiments were performed in 6 coating/drying cycles and at atomization air pressure of 1 bar, while other process conditions are shown in Table 6. Coefficient of variation is determined over a population of 100 tablets coated in every experiment, randomly selected out of approximately 700 tablets in a batch. Tablets were weighed before and after coating, and CV values were calculated from (10). Preliminary research showed the relationship between the droplet Reynolds number (1) and coefficient of variation (CV) (9). CV decreases with the increase of the droplet Reynolds number. Additionally, diluted solutions have lower viscosity which resulted in smaller droplets that are characterized with high Re values. Low viscosity makes those solutions more suitable for atomization occurring in the chamber. Although the differences in $\mathrm{CV}$ values are negligible, the more reasonable explanation arises from the droplet-surface impact study explained in Section 3.3 Furthermore, the content of poorly coated tablets was calculated. Each tablet in the batch of 700 tablets was visually analyzed. Tablets that were unevenly coated all over the surface were separated as bad-coated ones. Their mass content in the batch represents the value of PCT. The results (Table 6) led to a general conclusion that higher temperature ensures successful drying of the coating film and preventing the sticking of the tablets which could result in uneven coating. PCT content was generally lowered when temperature was raised from $50^{\circ} \mathrm{C}$ to $60^{\circ} \mathrm{C}$. Different concentrations of Advantia Prime coating solutions were examined, 2, 5, and $10 \mathrm{wt} . \%$. PCT content was increased with the increase of the mass flow rate and concentration of coating solution. As can be seen, highly viscous coating solution (10wt.\%) applied at low temperature led to poor coating on almost half a batch of tablets $(\mathrm{PCT}=49.7 \%)$. Considering the latter observations, the aim of this research is to reach the lowest possible $\mathrm{CV}$ and PCT content by multiplying cycles of the coating process, rather than increasing the concentration of coating solution. This assumption was loosely based on the fact that more spraying and drying cycles will induce better coverage of the surface and will also decrease imperfections on film morphology.

Considering all preliminary results, further research was performed at a low mass flow rate and concentration of coating solution, increased temperature of drying air, different atomization pressures, and increased number of coating/drying cycles (Table 4 ).

The results of present research are shown in Table 7.

The results showed minor deviations in $\mathrm{CV}$ values that were altogether slightly higher than in the preliminary experiments (Table 6). Detected deviations in the CV quality parameter might be the result of tablet-to-tablet sheltering in 


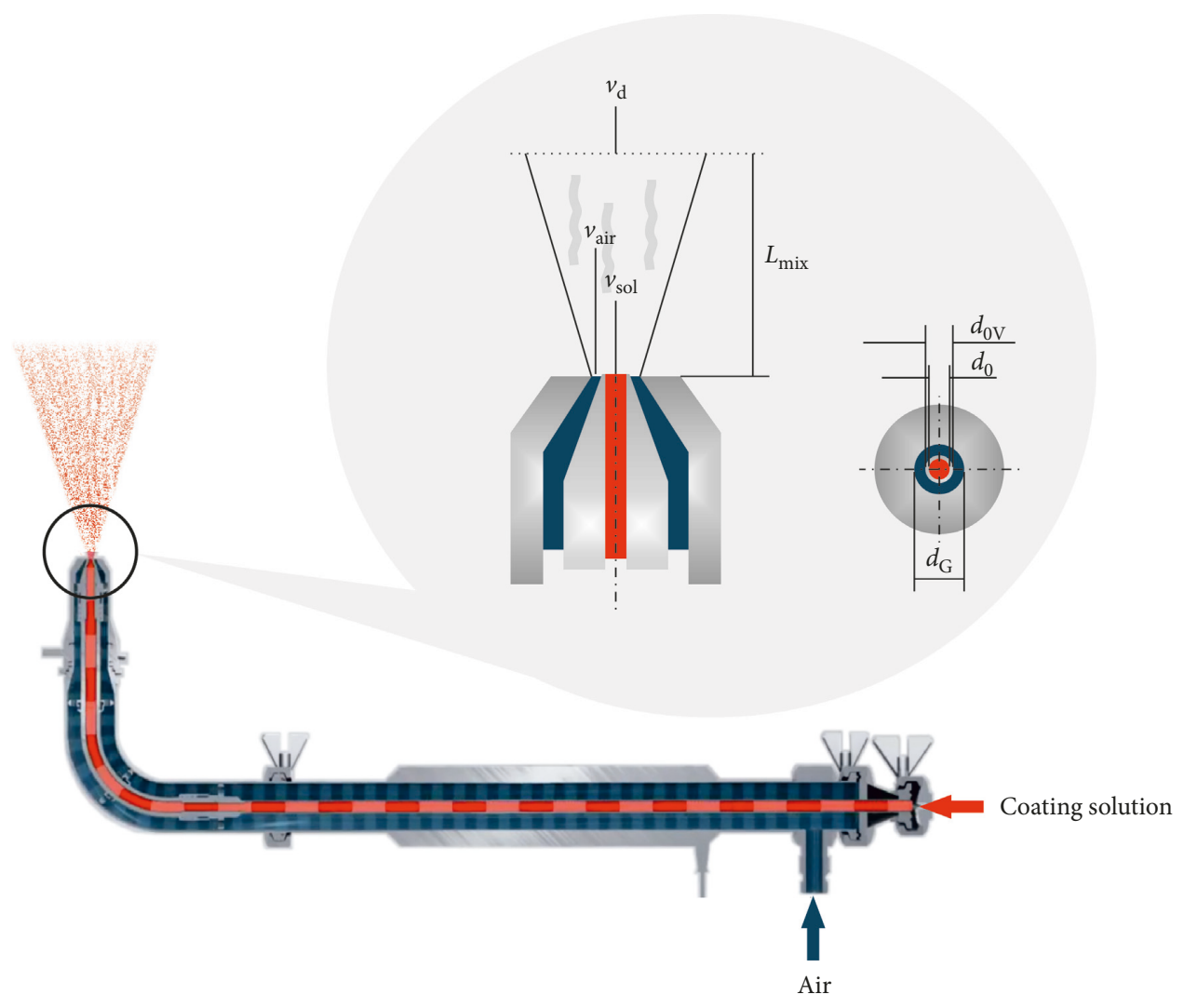

FIgURE 2: Schematic of the external mixing two-fluid nozzle.

TABLE 4: Process conditions during coating in fluid bed.

Mass flow rate of coating solution

Concentration of coating solution

Tablet mass

Distance of the Wurster partition

from the perforated plate

Nozzle diameter

Atomization pressure

Atomization air flow rate

Inlet air temperature

Coating period

Drying period

TABle 5: Experiments and their process conditions.

\begin{tabular}{lccccc}
\hline Experiment & $\mathrm{A}$ & $\mathrm{B}$ & $\mathrm{C}$ & $\mathrm{D}$ & $\mathrm{E}$ \\
\hline Temperature $\left({ }^{\circ} \mathrm{C}\right)$ & 60 & 67 & 67 & 67 & 67 \\
Atomization pressure (bar) & 1.0 & 1.0 & 1.2 & 2.0 & 1.4 \\
\hline
\end{tabular}

the coating region due to the significant number of tablets passing through the spray zone at a given time [5]. Furthermore, the drawback of this method is the fact that coated tablet weight, when it is coated properly, often equals the tablet weight in the case when coating layer adheres poorly or unevenly covers the surface. So, the mass of the coated tablets will not differ significantly from the median, resulting with low CV values. However, the quality of the coating film of such tablets is not acceptable. The mass of coated tablets may also vary due to the wear of the tablets in the fluidized bed. Moreover, compared to preliminary experiments that generally have lower $\mathrm{CV}$ values, it was concluded that $\mathrm{CV}$ is not the reliable quality parameter.

For that reason, poorly coated tablets were separated from the batches, and their content (PCT) was calculated. As explained, PCT content represents the mass fraction of tablets in the batch that were unevenly coated all over the entire surface (Table 7). Preliminary results showed lower PCT percentage at higher drying temperature $\left(60.0^{\circ} \mathrm{C}\right)$. Therefore experiments were performed at $60.0^{\circ} \mathrm{C}$ and $67^{\circ} \mathrm{C}$. Generally, it has been shown that the method of trial and error, when in line with a theoretical framework and process capability, may provide considerable process improvement. Increase in the mass of coating film was obtained due to the low solution concentration ( $2 \mathrm{wt} . \%)$ and increased number of coating/drying cycles. Low viscosity of the solution facilitated atomization process, while multiple coating cycles provided a more compact coating film. Higher temperature is beneficial in prevention of overwetting and sticking defects. Wet tablets preferentially stick to each other as well as to the walls or elements of the coating chamber (Figure 3).

Further experiments are directed primarily to the additional increase in atomization pressure and temperature, in order to obtain smaller droplets that will dry out faster. Accelerated evaporation is crucial for good adherence of new layers. Smaller droplets will dry faster ensuring dry surface of the tablet, thus prepared for the new coating cycle. This will prevent overwetting of the surface and sticking of the tablets which will result in a lower PCT content. It might enhance 
Table 6: Preliminary results [25].

\begin{tabular}{|c|c|c|c|c|c|}
\hline $\begin{array}{l}\text { Temperature } \\
\left({ }^{\circ} \mathrm{C}\right)\end{array}$ & $\begin{array}{l}\text { Mass flow rate of } \\
\text { coating solution } \\
\left(\mathrm{g} \cdot \mathrm{min}^{-1}\right)\end{array}$ & $\begin{array}{l}\text { Concentration of } \\
\text { coating solution } \\
\text { (wt. } \%)\end{array}$ & $\begin{array}{l}\text { Poorly coated } \\
\text { tablets content } \\
\text { (PCT) }(\%)\end{array}$ & $\begin{array}{l}\text { Droplet } \\
\text { Reynolds } \\
\text { number }\end{array}$ & $\begin{array}{l}\text { Intertablet } \\
\text { uniformity } \\
\text { (CV) }\end{array}$ \\
\hline 50 & 7.85 & 2 & 0.9 & 1672 & 0.0116 \\
\hline 50 & 9.90 & 2 & 9.9 & 1647 & 0.0126 \\
\hline 50 & 7.85 & 5 & 14.0 & 345 & 0.0150 \\
\hline 50 & 9.90 & 5 & 34.0 & 338 & 0.0170 \\
\hline 50 & 7.85 & 10 & 49.7 & 103 & 0.0170 \\
\hline 60 & 7.85 & 2 & 2.3 & 1672 & 0.0106 \\
\hline 60 & 9.90 & 2 & 3.6 & 1647 & 0.0132 \\
\hline 60 & 7.85 & 5 & 4.0 & 345 & 0.0146 \\
\hline 60 & 9.90 & 5 & 13.1 & 338 & 0.0166 \\
\hline
\end{tabular}

TABLE 7: CV and PCT content values for run process conditions.

\begin{tabular}{|c|c|c|c|c|}
\hline $\begin{array}{l}\text { Process } \\
\text { conditions }\end{array}$ & $\#$ & $\begin{array}{l}\text { Number } \\
\text { of cycles }\end{array}$ & $\mathrm{CV}$ & $\begin{array}{c}\text { PCT } \\
\text { content (\%) }\end{array}$ \\
\hline \multirow{3}{*}{ A: $60^{\circ} \mathrm{C} ; 1$ bar } & A1 & 10 & 0.0236 & 3.6 \\
\hline & $\mathrm{A} 2$ & 15 & 0.0273 & 20.9 \\
\hline & $\mathrm{A} 3$ & 20 & 0.0254 & 18.2 \\
\hline \multirow{6}{*}{ B: $67^{\circ} \mathrm{C} ; 1$ bar } & B1 & 6 & 0.0269 & 0.0 \\
\hline & B2 & 10 & 0.0273 & 0.0 \\
\hline & B3 & 15 & 0.0257 & 3.7 \\
\hline & B4 & 20 & 0.0237 & 5.6 \\
\hline & B5 & 25 & 0.0255 & 6.0 \\
\hline & B6 & 30 & 0.0250 & 2.2 \\
\hline \multirow{6}{*}{$\mathrm{C}: 67^{\circ} \mathrm{C} ; 1.2 \mathrm{bar}$} & $\mathrm{C} 1$ & 6 & 0.0258 & - \\
\hline & $\mathrm{C} 2$ & 10 & 0.0266 & 0.1 \\
\hline & $\mathrm{C} 3$ & 15 & 0.0228 & 0.0 \\
\hline & $\mathrm{C} 4$ & 20 & 0.0257 & 0.0 \\
\hline & C5 & 25 & 0.0241 & 1.5 \\
\hline & C6 & 30 & 0.0241 & 3.3 \\
\hline \multirow[b]{2}{*}{$\mathrm{D}: 67^{\circ} \mathrm{C} ; 2.0 \mathrm{bar}$} & D1 & 20 & 0.0228 & - \\
\hline & $\begin{array}{l}\text { D1- } \\
\text { II }\end{array}$ & 20 & 0.0248 & - \\
\hline $\mathrm{E}: 67^{\circ} \mathrm{C} ; 1.4$ bar & E1 & 25 & 0.0221 & 1.1 \\
\hline
\end{tabular}

intratablet coating uniformity as well, since increased number of faster and smaller droplets will now spread more evenly and create a thinner film.

PCT content is significantly lowered when air temperature is increased to $67^{\circ} \mathrm{C}$ (Table 7). The high value of air pressure (Table 7; D1 and D1-II) and low number of coating/drying cycles (Table 7; C1) resulted in thin film coats that were hardly visible which caused minor difficulties related to intertablet uniformity perceptibility. Consequently, PCT content could not be determined for those experiments.

Coatings obtained in $\mathrm{B}$ and $\mathrm{C}$ set of experiments are much more uniform than those in A series. Most of the poorly coated tablets in A series refer to the tablets that stuck on the internal surface of the Wurster tube. It is important to emphasize that no tablets stuck to the Wurster tube in experiments B2, D1-II, or $\mathrm{C} 1, \mathrm{C} 3$, and $\mathrm{C} 4$. Altogether, results show that a set of experiments performed in $\mathrm{C}$ series are sufficient for running an effective and efficient coating process using atomization pressure of 1.2 bar and temperature of $67^{\circ} \mathrm{C}$ producing the low content of poorly coated tablets.
3.2. Stereomicroscopy. Stereomicroscopy is potentially useful for intra- and intertablet uniformity assessment. Initially, the idea was to gather the stereomicrographs of all coated tablets in order to establish the 1-10 grade scale and carry out the coating quality evaluation. However, the aggravating issue here is that there are more than 700 tablets in each batch. It is practically impossible to analyze every single one of them, compare them, and to rate the quality for each coating.

Anyway, a worthwhile stereomicroscopic analysis has been carried out. Several tablets from each experiment were meticulously examined. Stereomicroscopy analysis revealed various "volcano craters" (Figure 4), "bitten off," and berrylike structures spread all over the tablet surfaces, whereas on the well-coated tablets, there are several minor or almost intangible differences that scarcely lend themselves to description. However, flat and even surface (Figure 5) cannot be precisely characterized by the stereomicroscope, thus being another reason to seek for a more sophisticated method.

3.3. Droplet-Surface Impact Regime. Impact regime determination is based on dimensionless numbers as this gave rise to a solid connection between process conditions and the morphology of the coating layer.

Figure 6 represents illustration of coating mechanisms through relationship of Ohnesorge and Reynolds number. A well-known Mundo et al. deposition diagram [26] gives empirical critical curve that represents the transition in deposition-splashing mechanism where critical constant $\left(K_{\text {crit }}\right)$ is defined as the ratio of Ohnesorge and Reynolds number $\left(\mathrm{Oh} / \mathrm{Re}^{-1.25}\right)$. It can be seen that our results fall in the area of deposition mechanism for 5 experimental conditions given in Table 5 . However, only 4 points were obtained because experiments A and B were performed at same atomization pressure which gave similar values of Reynolds and Ohnesorge numbers. Reynolds number was calculated according to (1), Ohnesorge number from (2), while droplet velocity and its size were calculated using (15) and (8). When the droplet hits the dry and solid surface, it can rebound from it, deposit on the surface, or splash with secondary drops due to more energetic impact. If the droplet deposits on the surface, it will form a liquid film [26] which is a preferable mechanism for film coating. 


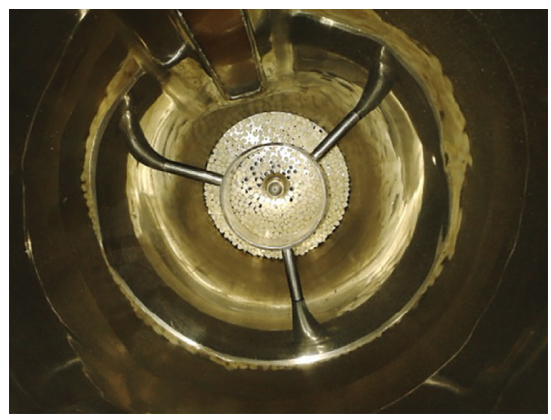

(a)

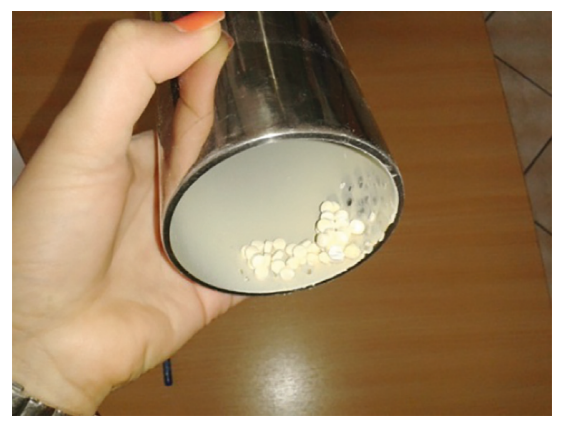

(b)

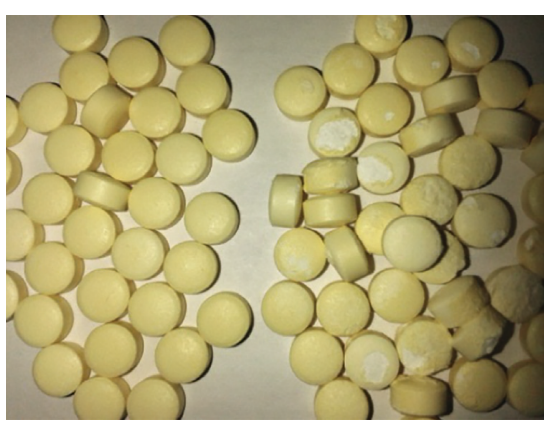

(c)

Figure 3: Photographs of the coating chamber filled with tablets, tablets stuck on Wurster tube, and coated tablets.

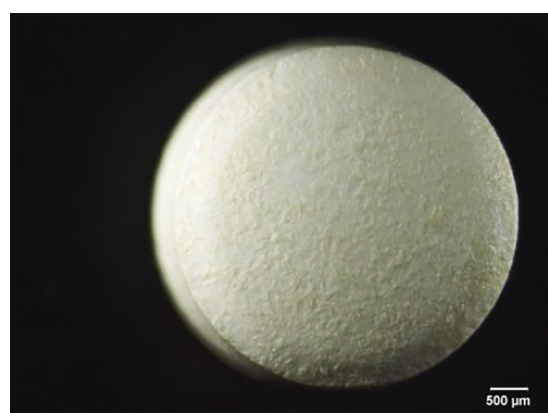

(a)

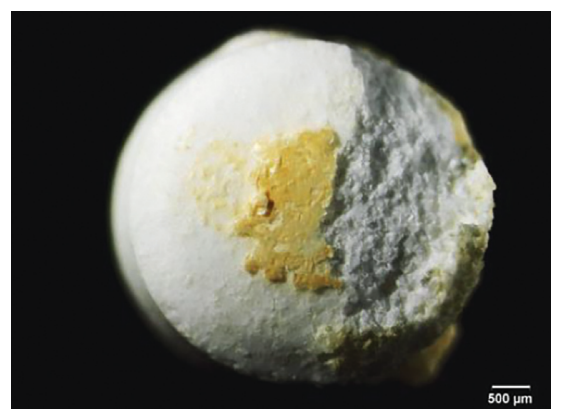

(b)

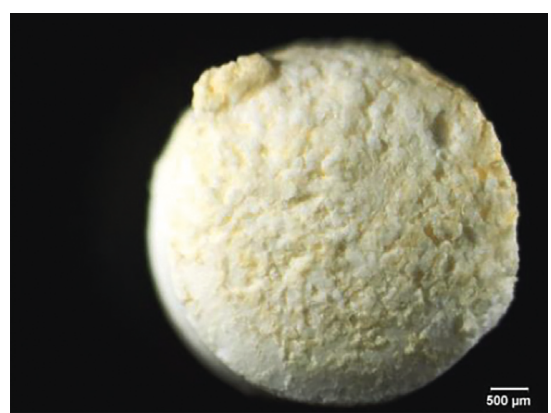

(c)

FIgURE 4: Stereomicrographs: experiment A1-well-coated tablet versus badly-coated tablet (both sides).

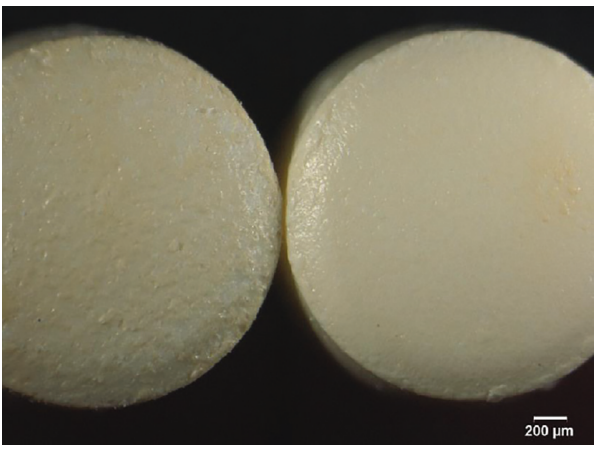

FIGURE 5: Stereomicrograph of well-coated tablet from experiment A3 compared to C2.

Figure 7 illustrates the impact regime map as defined by Schiaffino and Sonin [27]. Four impact regimes are distinguished: collision for inviscid and viscous fluids as well as the capillary-driven region for both types of fluids. When all four regimes are divided by assuming Ohnesorge, Weber, and Reynolds number equals to unity, transition lines could be plotted [27-29]. According to obtained results, experimental data fall within the region of high Weber number in the area of inviscid fluid and collision as a prevailing mechanism. According to 5 experimental conditions given in Table 5, only 4 points were obtained because experiments $\mathrm{A}$ and $\mathrm{B}$ were performed at same atomization pressure, resulting with same droplet velocity which gave similar values of Weber number.

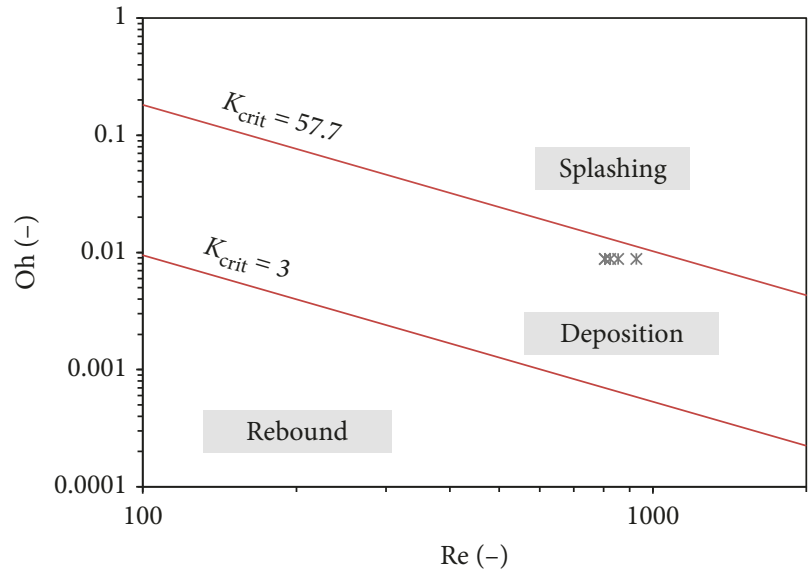

FIgure 6: Impact mechanism diagram [26] of experiments A-E.

Inviscid, impact-driven region assumes that droplet spreading occurs in a short period where the flow is driven by the dynamic pressure of impact [27]. Due to intense collision (splashing) of droplets, there is a risk of absorption of coating solution through the pores in the tablet structure. However, tablets were made by pressing, and the pores are not exposed which resulted in formation of surface coating film.

Khoufech et al. [16] have described droplet adherence to the surface analyzed through $\mathrm{We}-\mathrm{Oh}$ relation. They have experimented with CMC (carboxymethyl cellulose) which 


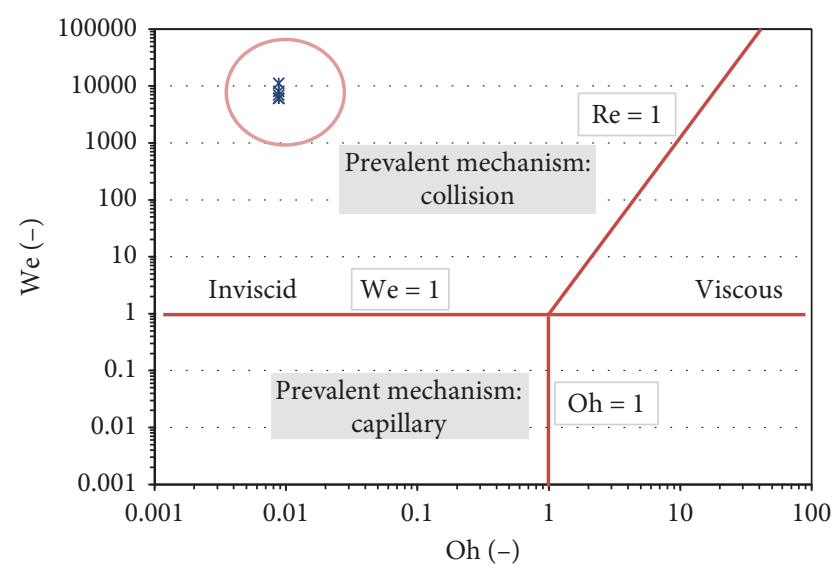

Figure 7: Impact regime diagram [27] of experiments A-E.

is widely used for pharmaceutical production and coatings as well. It has valuable properties in API release and can be used in polymer blends with HPC. Assuming they are both water soluble and share few other properties (viscoelasticity and shear-thinning), experiments are comparable. As their theory suggests, step out of the area of collision and splashing dominance is reached only with 5\% polymer concentration in coating formulation. Unfortunately, we have encountered technical issues due to significantly increased viscosity of 5\% solution of Advantia Prime (15.6 mPa.s).

The impact regime can be successfully adjusted by droplet-surface adherence investigation. At high Weber number values, spreading is driven by impact velocity. Weber number, defined as the ratio of kinetic and surface energy, decreases when droplet size lowers (higher $\mathrm{We} \rightarrow$ higher $\left.\beta_{\max }\right)$. Smaller droplets move faster, and according to Toivakka [9], high velocity implies higher collision energy, therefore enhanced spreading over the surface. Figure 8 illustrates the influence of Weber and Reynolds numbers on the maximum spreading factor, ratio of maximum droplet spreading diameter, and droplet diameter before collision calculated according to Roisman [15], (6). Results showed that the increase in Reynolds and Weber numbers would lead to the increase in the maximum spreading factor due to the intense impact of the coating droplet and high kinetic energy. This is consistent with results obtained by Bolleddula et al. [28] and Asai et al. [12].

\section{Conclusions}

Following our intention to perform the coating process more efficiently, many experimental runs have been provided for placebo tablets in a lab-scale fluid-bed environment with a Wurster tube.

Using CV and PCT content with coating layer adherence and its consistency as process quality metrics, favorable process conditions have been detected.

Increasing number of coating cycles is found to significantly contribute to better film morphology in the case of sufficiently high temperatures.

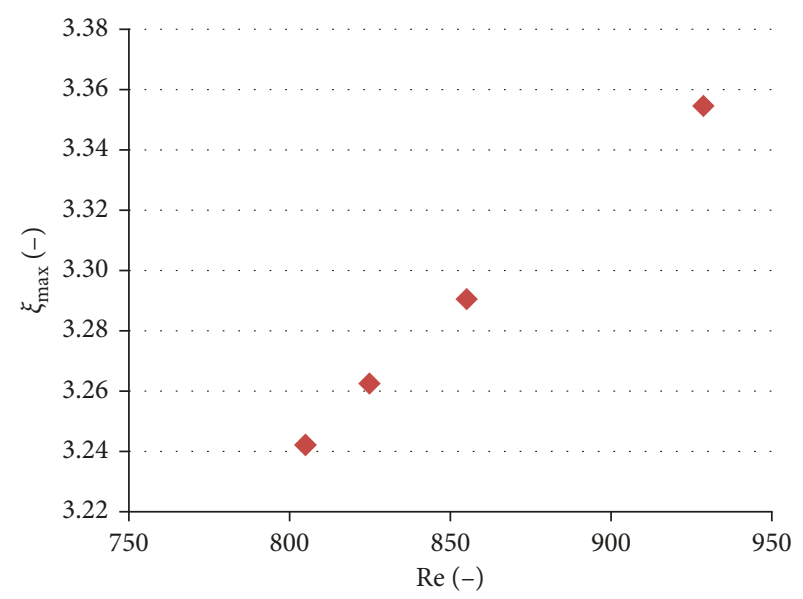

(a)

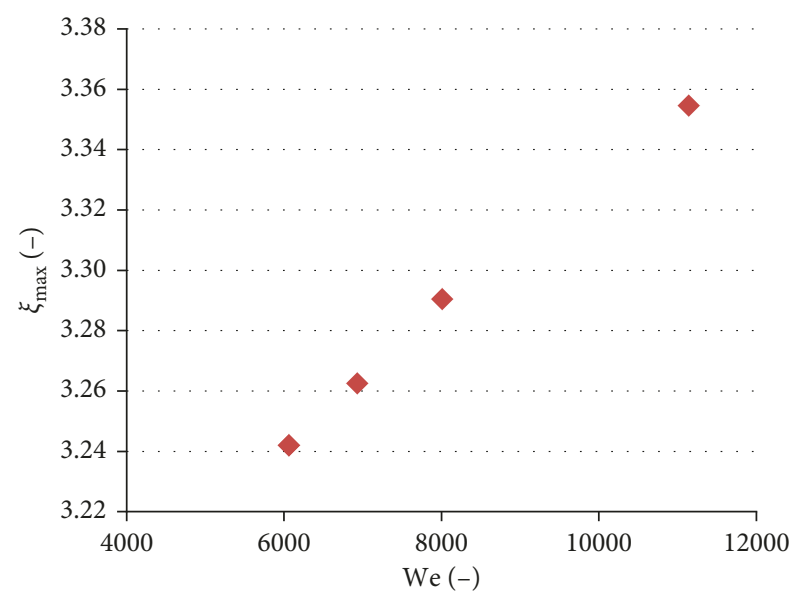

(b)

FIgURE 8: Diagrams presenting the relation between the maximum spreading factor and dimensionless Re and We numbers in experiments A-E.

This paper reveals a mechanistic perspective on the complex phenomena occurring on a tablet surface during coating process. Impact regime and impact mechanism diagrams are successfully defined for the system studied. Provided diagrams suggest efficient process conditions for the process with good quality metrics.

Deposition is found to be a preferential mechanism for conditions studied. Furthermore, collision is addressed as a prevalent impact regime.

Droplet breakup occurrence in terms of droplet diameter was efficiently correlated with hydrodynamic conditions.

\section{Notations}

$A_{\mathrm{G}}: \quad$ Cross section of nozzle $\left(\mathrm{m}^{2}\right)$

Ar: $\quad$ Archimedes number

CV: Coefficient of variation

$D: \quad$ Droplet mean diameter before impact $(\mathrm{m})$

$d_{\mathrm{G}}$ : $\quad$ Outer diameter of nozzle (air flow) (m)

$D_{\max }: \quad$ Maximum droplet diameter after impact $(\mathrm{m})$

$d_{0 \mathrm{~V}}: \quad$ Inner diameter of nozzle (liquid flow) $(\mathrm{m})$ 
$d_{0}: \quad$ Nozzle diameter $(\mathrm{m})$

$d_{\mathrm{p}}: \quad$ Particle (droplet) size $(\mathrm{m})$

$d_{\mathrm{s}}: \quad$ Equivalent surface diameter of tablet $(\mathrm{m})$

$d_{\mathrm{V}}: \quad$ Equivalent volume diameter of tablet $(\mathrm{m})$

$D_{32}$ : $\quad$ Sauter's droplet diameter $(\mathrm{m})$

$D_{50}: \quad$ Droplet median diameter $(\mathrm{m})$

F: $\quad$ Friability (\%)

$K_{\text {crit }}: \quad$ Critical constant $\left(\mathrm{Oh} / \mathrm{Re}^{-1.25}\right)$

$\dot{M}_{\text {sol }}$ : Mass flow rate of solution $\left(\mathrm{kg} \cdot \mathrm{s}^{-1}\right)$

$\dot{M}_{\text {air }}: \quad$ Mass flow rate of air $\left(\mathrm{kg} \cdot \mathrm{s}^{-1}\right)$

$\bar{m}_{\mathrm{c}}: \quad$ Mean mass of coated tablets $(\mathrm{kg})$

$m_{\mathrm{c}, i}: \quad$ Mass of one coated tablet $(\mathrm{kg})$

$m_{1}$ : Mass of tablets before the friability test $(\mathrm{kg})$

$m_{2}$ : $\quad$ Mass of tablets after the friability test $(\mathrm{kg})$

$N$ : Number of analyzed tablets (11)

Oh: Ohnesorge number

$R: \quad$ Capillary diameter $(\mathrm{m})$

Re: $\quad$ Reynolds number

$t: \quad$ Time (s)

$\dot{V}_{\text {air }}: \quad$ Volume flow rate of air $\left(\mathrm{m}^{3} \cdot \mathrm{s}^{-1}\right)$

$v_{\mathrm{d}}: \quad$ Droplet velocity $\left(\mathrm{m} \cdot \mathrm{s}^{-1}\right)$

$v_{\mathrm{mf}}: \quad$ Minimal fluidization velocity $\left(\mathrm{m} \cdot \mathrm{s}^{-1}\right)$

$v_{\mathrm{REL}}: \quad$ Relative velocity $\left(\mathrm{m} \cdot \mathrm{s}^{-1}\right)$

We: Weber number

$\gamma_{\text {liq }}: \quad$ Liquid surface tension $\left(\mathrm{N} \cdot \mathrm{m}^{-1}\right)$

$\Delta p: \quad$ Pressure drop $(\mathrm{Pa})$

$\Delta p_{\text {air }}: \quad$ Atomization pressure (bar)

$\xi_{\max }: \quad$ Maximum spreading factor

$\mu: \quad$ Fluid viscosity (Pa.s)

$\rho: \quad$ Fluid density $\left(\mathrm{kg} \cdot \mathrm{m}^{-3}\right)$

$\rho_{\text {air }}: \quad$ Air density $\left(\mathrm{kg} \cdot \mathrm{m}^{-3}\right)$

$\rho_{\text {sol }}: \quad$ Solution density $\left(\mathrm{kg} \cdot \mathrm{m}^{-3}\right)$

$\rho_{\mathrm{p}}: \quad$ Particle (tablet) density $\left(\mathrm{kg} \cdot \mathrm{m}^{-3}\right)$

$\sigma: \quad$ Standard deviation of mass $(\mathrm{kg})$

$\psi_{\text {Wa }}: \quad$ Wadell's sphericity factor

API: Active pharmaceutical ingredient

CV: Coefficient of variation (intertablet uniformity)

CMC: Carboxymethyl cellulose

EC: Ethyl cellulose

HPC: Hydroxypropyl cellulose

HPMC: Hydroxypropyl methylcellulose

MCC: Microcrystalline cellulose

PEG: Polyethylene glycol

PCT: Poorly coated tablets content.

\section{Data Availability}

The data used to support the findings of this study are available from the corresponding author upon request.

\section{Conflicts of Interest}

The authors declare that they have no conflicts of interest.

\section{References}

[1] M. Benković and I. Bauman, "Oblaganje čestica u prehrambenoj industriji," Croatian Journal of Food Technology, Biotechnology and Nutrition, vol. 6, pp. 13-24, 2011.
[2] B. Guignon, A. Duquenoy, and E. D. Dumoulin, "Fluid bed encapsulation of particles: principles and practice," Drying Technology, vol. 20, no. 2, pp. 419-447, 2002.

[3] J. Pranjić, "Oblaganje u fluidiziranom sloju Wurster tehnologijom," M.S. thesis, University of Zagreb, Zagreb, Croatia, 2013.

[4] E. Teunou and D. Poncelet, "Batch and continuous fluid bed coating-review and state of the art," Journal of Food Engineering, vol. 53, no. 4, pp. 325-340, 2002.

[5] S. Shelukar, J. Ho, J. Zega et al., "Identification and characterization on factors controlling tablet coating uniformity in a Wurster coating process," Powder Technology, vol. 110, no. 1-2, pp. 29-36, 2000.

[6] T. Havaić, "Fenomeni sudara kapi u procesu oblaganja Wurster tehnologijom," M.S. thesis, University of Zagreb, Zagreb, Croatia, 2016.

[7] S. Rujivipat, "Novel formulation and processing aspects for compression-coated tablets and for the compression of polymer-coated multiparticulates," Dissertation zur Erlangung des akademischen Grades des Doktors der Naturwissenschaften, Fachbereich Biologie, Chemie, Pharmazie der Freien Universität Berlin, Berlin, Germany, 2010.

[8] S. R. L. Werner, J. R. Jones, A. H. J. Paterson, R. H. Archer, and D. L. Pearce, "Air-suspension coating in the food industry: Part II-micro-level process approach," Powder Technology, vol. 17, no. 1, pp. 34-45, 2007.

[9] M. Toivakka, "Numerical investigation of droplet impact spreading in spray coating of paper," in Proceedings of 2003 TAPPI 8th Advanced Coating Fundamentals Symposium, Chicago, IL, USA, May 2003.

[10] A. Khoufech, M. Benali, and K. Saleh, "Influence of liquid formulation and impact conditions on the wetting of hydrophobic surfaces by aqueous polymeric solutions," Chemical Engineering Research and Design, vol. 110, pp. 233-244, 2016.

[11] D. Izbassarov and M. Muradoglu, "Effects of viscoelasticity on drop impact and spreading on a solid surface," Physical Review Fluids, vol. 1, no. 2, article 023302, 2016.

[12] A. Asai, M. Shioya, S. Hirasawa, and T. Okazaki, "Impact of an ink drop on a paper," Journal of Imaging Science and Technology, vol. 37, pp. 205-207, 1993.

[13] X. X. Cheng and R. Turton, "The prediction of variability occurring in fluidized bed coating equipment. II. The role of nonuniform particle coverage as particles pass through the spray zone," Pharmaceutical Development and Technology, vol. 5, no. 3, pp. 323-332, 2000.

[14] M. Pasandideh-Fard, Y. M. Qiao, S. Chandra, and J. Mostaghimi, "Capillary effects during droplet impact on a solid surface," Physics of Fluids, vol. 8, no. 3, pp. 650-659, 1996.

[15] I. Roisman, "Inertia dominated drop collisions. II. An analytical solution of the Navier-Stokes equations for a spreading viscous film," Physics of Fluids, vol. 21, no. 5, article 052104, 2009.

[16] A. Khoufech, M. Benali, and K. Saleh, "Influence of liquid formulation and impact conditions on the coating of hydrophobic surfaces," Powder Technology, vol. 270, pp. 599-611, 2015.

[17] P. D. Hede, P. Bach, and A. D. Jensen, "Two-fluid spray atomisation and pneumatic nozzles for fluid bed coating/ agglomeration purposes: a review," Chemical Engineering Science, vol. 63, no. 14, pp. 3821-3842, 2008.

[18] S. Romero-Torres, J. D. Pérez-Ramos, K. R. Morris, and E. R. Grant, "Raman spectroscopy for tablet coating thickness 
quantification and coating characterization in the presence of strong fluorescent interference," Journal of Pharmaceutical and Biomedical Analysis, vol. 41, no. 3, pp. 811-819, 2006.

[19] J. F. Kauffman, M. Dellibovi, and C. R. Cunningham, "Raman spectroscopy of coated pharmaceutical tablets and physical models for multivariate calibration to tablet coating thickness," Journal of Pharmaceutical and Biomedical Analysis, vol. 43, no. 1, pp. 39-48, 2007.

[20] A. Ariyasu, Y. Hattori, and M. Otsuka, "Non-destructive prediction of enteric coating layer thickness and drug dissolution rate by near-infrared spectroscopy and X-ray computed tomography," International Journal of Pharmaceutics, vol. 525, no. 1, pp. 282-290, 2017.

[21] M. Haaser, K. C. Gordon, C. J. Strachan, and T. Rades, "Terahertz pulsed imaging as an advanced characterisation tool for film coatings-a review," International Journal of Pharmaceutics, vol. 457, no. 2, pp. 510-520, 2013.

[22] Y. Dong, H. Lin, V. Abolghasemi, L. Gan, J. A. Zeitler, and Y.-C. Shen, "Investigating intra-tablet coating uniformity with spectral-domain optical coherence tomography," Journal of Pharmaceutical Sciences, vol. 106, no. 2, pp. 546-553, 2017.

[23] European Pharmacopoeia, EDQM, European Pharmacopoeia 01/2010:20907 Friability of Uncoated Tablets, Council of Europe, Strasbourg, France, 8th edition, 2013.

[24] G. Toschkoff and J. G. Khinast, "Mathematical modeling of the coating process," International Journal of Pharmaceutics, vol. 457, no. 2, pp. 407-422, 2013.

[25] G. Matijašić, K. Žižek, M. Gretić, A.-M. Đumbir, T. Havaić, and M. Bokulić, "Fluid-bed coating with Wurster insert," in Proceedings of 5th Croatian Meeting of Chemist and Chemical Engineers, Book of Abstract, Zagreb, Croatia, 2015.

[26] C. Mundo, M. Sommerfeld, and C. Tropea, "Droplet-wall collisions: experimental studies of the deformation and breakup process," International Journal of Multiphase Flow, vol. 21, no. 2, pp. 151-173, 1995.

[27] S. Schiaffino and A. A. Sonin, "Molten droplet deposition and solidification at low Weber," Physics of Fluids, vol. 9, no. 11, pp. 3172-3187, 1997.

[28] D. A. Bolleddula, A. Berchielli, and A. Aliseda, "Impact of a heterogeneous liquid droplet on a dry surface: application to the pharmaceutical industry," Advances in Colloid and Interface Science, vol. 159, no. 2, pp. 144-159, 2010.

[29] T. Lim, S. Han, J. Chung, J. T. Chung, S. Ko, and C. P. Grigoropoulos, "Experimental study on spreading and evaporation of inkjet printed pico-liter droplet on a heated substrate," International Journal of Heat and Mass Transfer, vol. 52, no. 1-2, pp. 431-441, 2009. 


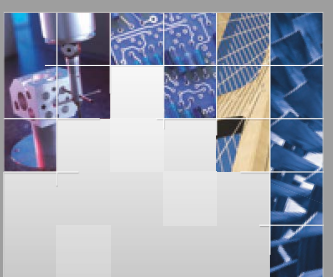

\section{Enfincering}
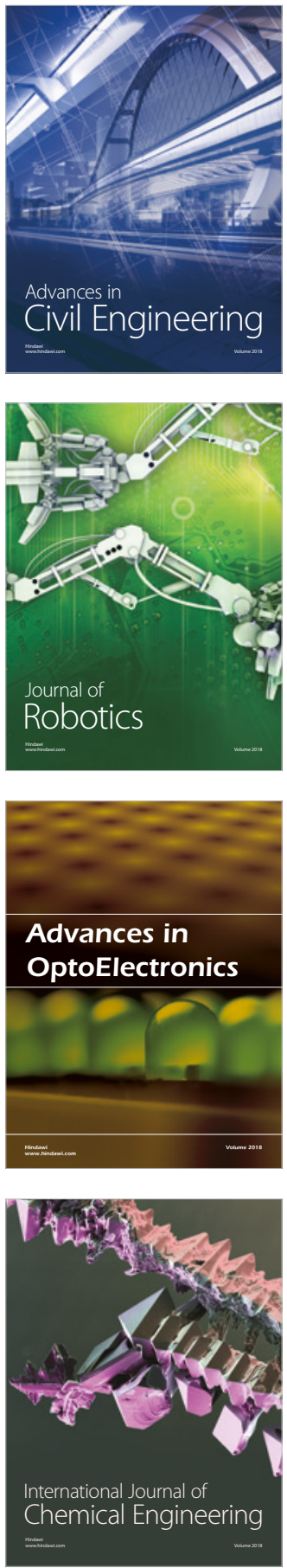

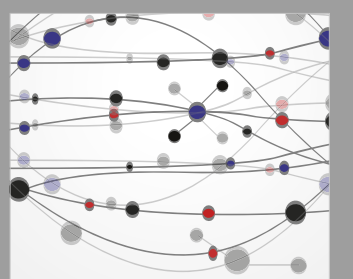

\section{Rotating \\ Machinery}

The Scientific World Journal

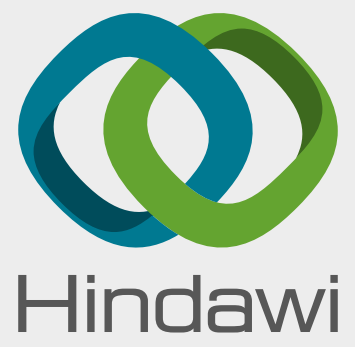

Submit your manuscripts at

www.hindawi.com
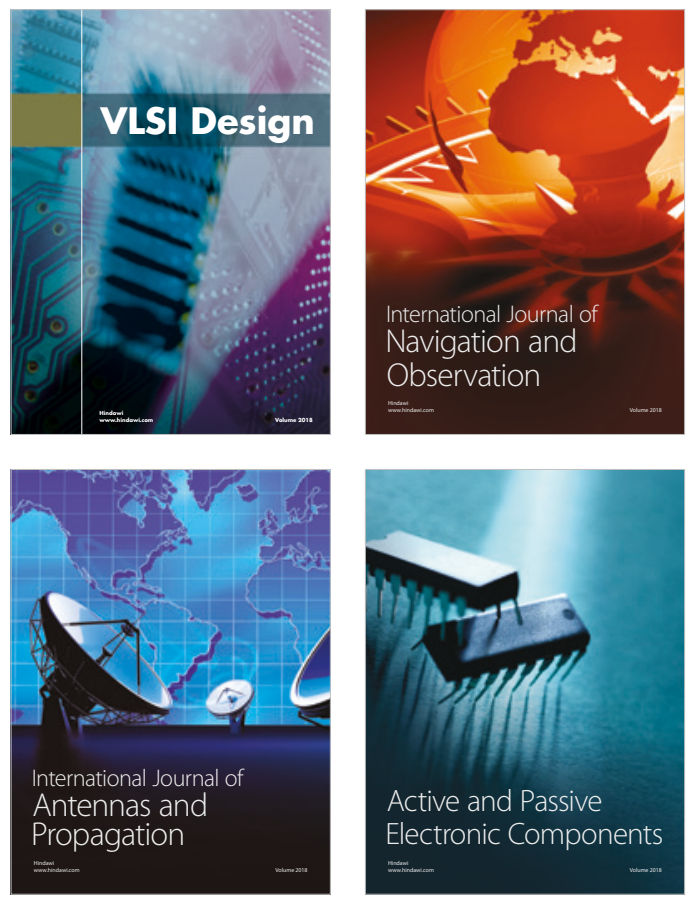
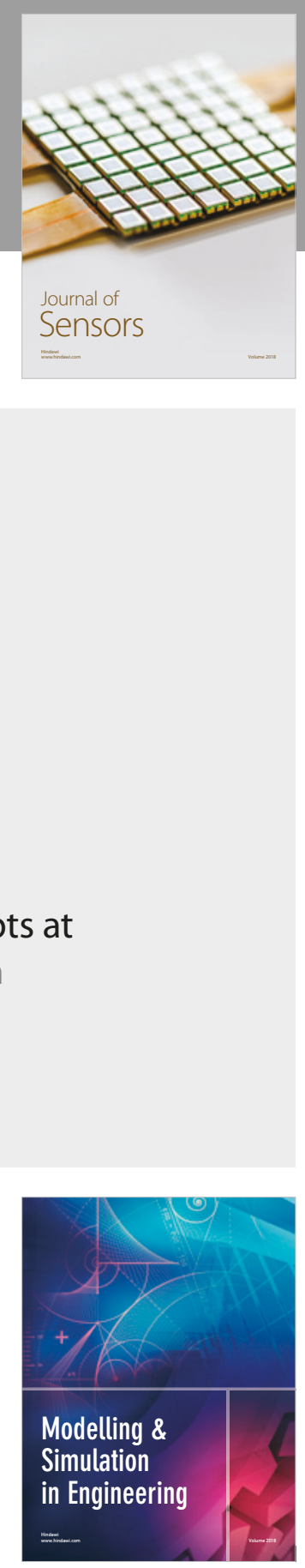

\section{Advances \\ Multimedia}
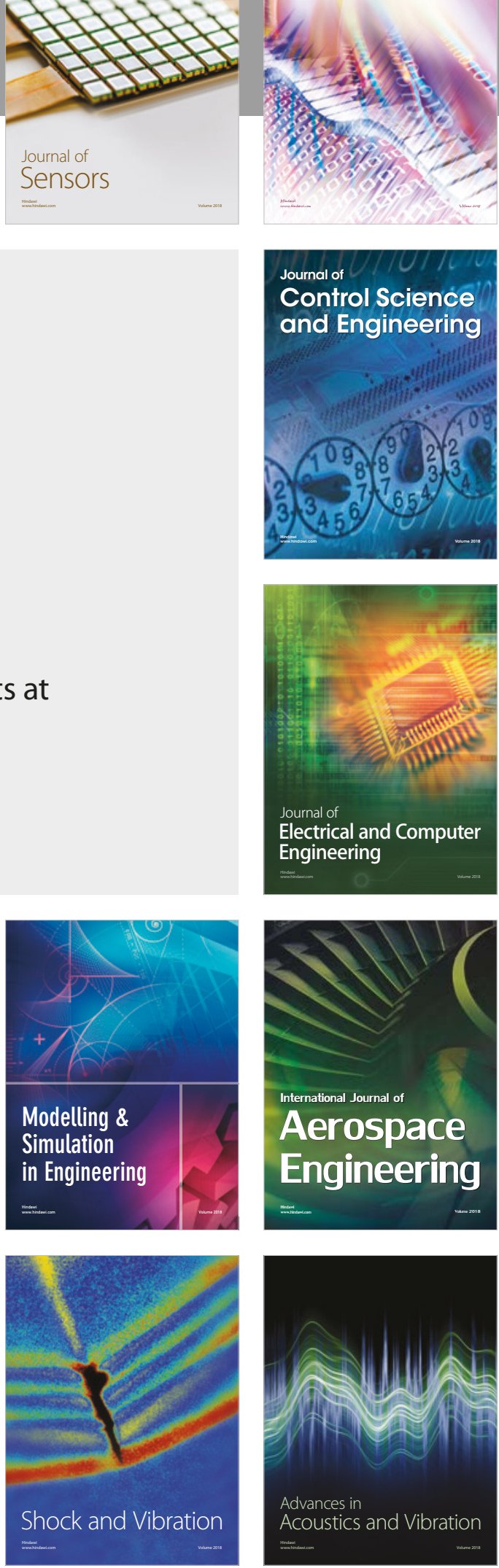